\title{
Advances in cryogenic chilling technology for deep mines
}

\author{
DL Cluff University of Exeter, Camborne School of Mines and CanMIND Associates, UK \\ PJ Foster University of Exeter, Camborne School of Mines, UK
}

\begin{abstract}
Deep mining presents a challenging environment for materials handling, but geotechnical and thermodynamic aspects are among the most problematic. In this paper, the development of cryogenic chilling and the impact of ancillary cryogenic technologies is discussed.

Cryogenic chilling is a straight forward system based on technologies that have benefited from over a century of engineering; thus, are reliable and easily purchased from numerous suppliers. As the depth increases, the simple extension of the delivery piping and installation of local storage and vaporiser systems is all that is required. There is no return circuit required as the liquid exits the vaporiser to become part of the ventilation airflow. This paper will provide an understanding of the physics of cryogenic chilling and preliminary designs of the technologies required to deliver the chilling.

The concept of chilling on demand is discussed in terms of providing consistent temperatures given varying heat loads. The introduction of electric vehicles to deep mining has the impact of potentially reducing the ventilation flow by 40 to $50 \%$ of that required by legislation when diesel equipment is in use; however, this leads to a high susceptibility to larger temperature changes for lesser amounts of heat introduced. This can be problematic if the flow cannot be increased to carry the heat away, say, just after a blast or in an area that has several electric vehicles in operation, which could produce temperatures beyond the allowable working limits rather quickly. Cryogenic chilling is an on demand system, able to respond rapidly by simply increasing the liquid flow. Not only does the liquid air provide chilling, it replaces some of the air that would be drawn from the surface, which can significantly reduce the main fan power.
\end{abstract}

The concept of cryogenic chilling provides an opportunity for a chilling option that has additional uses, which can be implemented to offset the capital expenditure due to economies of scale. The scaling factor for a liquid air plant is about 0.45 , so doubling the capacity from 2,000 to 4,000 tpd requires only $36 \%$ more capital expenditure and allows for the option to take advantage of ancillary markets such as the sale of oxygen and argon to the industrial market. Since mines are often remote, energy is expensive, but a cryogenic energy storage system in conjunction with wind or solar power provides for a greater energy penetration. A brief discussion of the energy storage technology is provided in the introduction. Availability of liquid air also provides the opportunity for compressed air on demand systems that deliver chilling simultaneously. An emerging cryogenic vehicle technology from the Dearman Engine Company does the exact opposite of diesel engines; for a $100 \mathrm{~kW}$ Dearman engine, about $200 \mathrm{~kW}$ of cooling is concurrently delivered in situ. In the near future a techno-economic analysis for the total cost of ownership comparison between a Dearman engine versus a diesel engine will be provided.

Keywords: underground mine environment, mine chilling, cryogenic chilling, liquid air energy storage

\section{Introduction}

\subsection{Cryogenic liquids production and storage}

The cryogenic liquids are produced on the surface in a standard cryogenic liquefaction plant, the main feature of a cryogenic energy storage (CES) system, which is comprised of a charging system, an energy storage section and a discharging system. The standard industrial air liquefaction plant or charging system uses the electrical energy from the grid or a renewable energy project to power the heat rejection process. 
The process creates liquid air, a cryogenic liquid at temperatures near $-196^{\circ} \mathrm{C}(78 \mathrm{~K})$. The liquid air is stored in a low-pressure insulated tank, an easily accessed energy storage repository, with minimal risk to the environment or personnel except for the very cold temperatures that one could accidentally be exposed to in the event of a leak or rupture. At the appropriate time that power is required, either when the price is high or the renewable system is inactive, liquid air is pumped to about $7 \mathrm{MPa}(1,000 \mathrm{psi})$ and evaporated through a turbine system (Brett \& Barnett 2014). The evaporation and subsequent expansion of the air as it increases in temperature by absorption of heat from the ambient surroundings, produces gaseous air that is capable of providing the pressure necessary to power the turbine resulting in useful work to generate electricity.

In Figure 1, the hot and cold storage are a means of increasing the efficiency of the system. The heat rejected from the compression stage in the liquefaction process is stored in an insulated container using rock or concrete as a storage medium, and is injected into the air during the expansion stage to produce the electricity. The cold created during the evaporative cooling is stored for use in the liquefaction process. The source of the hot and cold can be external and additive as well. Heat from industrial process or cold from the expansion of liquid natural gas can significantly increase the round trip efficiency of energy arbitrage (Brett \& Barnett 2014). The hot and cold can also be used for other purposes in mining, such as redirecting the heat to the downcast shaft in winter to warm the air. The cold is of significant interest because the placement of the turbines or power recovery unit (PRU) underground allows for the simultaneous production of electricity and chilling, and the elimination of the cryogenic pumps needed to produce $7 \mathrm{MPa}(1,000 \mathrm{psi})$, because the pressure head can be exploited.

Power Input Charging Infrastructure

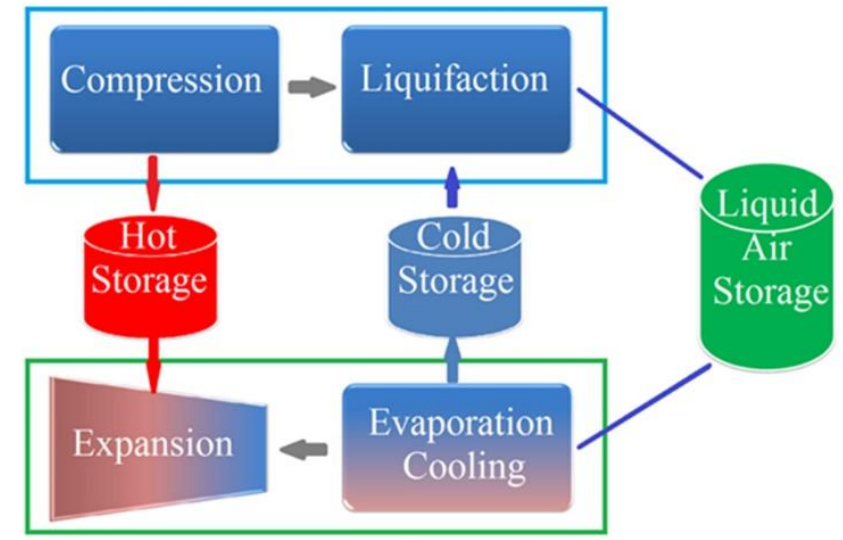

Discharging Infrastructure Power Output

Figure 1 Simplified schematic of a cryogenic energy storage system

In the following sections, the preliminary designs of the chilling, compressed air and electrical production technologies will be discussed.

\section{Cryogenic chilling technology}

A computational fluid dynamics model was created to simulate chilling by a $\mathrm{Cryofan}^{\mathrm{TM}}$ vaporiser. The model $^{2}$ is comprised of a heat exchanger, to allow the latent heat of vaporisation to be absorbed by the liquid flow, and gaseous venting outlets, where the air sourced from the cryogenic liquid exhausts to the airflow in the downcast shaft. The chilling system is placed directly into the downcast shaft to reduce the model complexity, and correspondingly, the computation time for a given simulation. For example, in Figure 2 , it can be seen that there is no piping connection from the heat exchanger to the cryogen-sourced gaseous outlets, as this would add significant CPU time to compute the advanced narrow channel refinement necessary to calculate the flow in the pipe. In a physical system, this equipment would clearly be adjacent to, rather than in, the downcast shaft. It is reasonable to assume that the mass flow from the heat exchanger will remain contained and flow to the cryogen sources gas outlets; therefore, by placing the outlets at the expected position for a design and applying the appropriate boundary conditions, the 
simplified model can be run under various initial conditions more frequently. At an appropriate time, wherein the main features of the design are determined to be assessed reasonably well, a more complex design can be implemented. The model is used to study the interaction of a cryogenic chilling system given the assumed conditions in a shaft at various depths and initial conditions. A cross-section of the shaft with the host rock properties and ambient air conditions is shown in Figure 2. The ambient inlet conditions, a pressure of $124.97 \mathrm{kPa}$ and temperature of about $46^{\circ} \mathrm{C}$, are set to simulate the conditions of the air at a depth of $1,915 \mathrm{~m}$, after the effect of auto-compression, and are derived from the surface conditions.

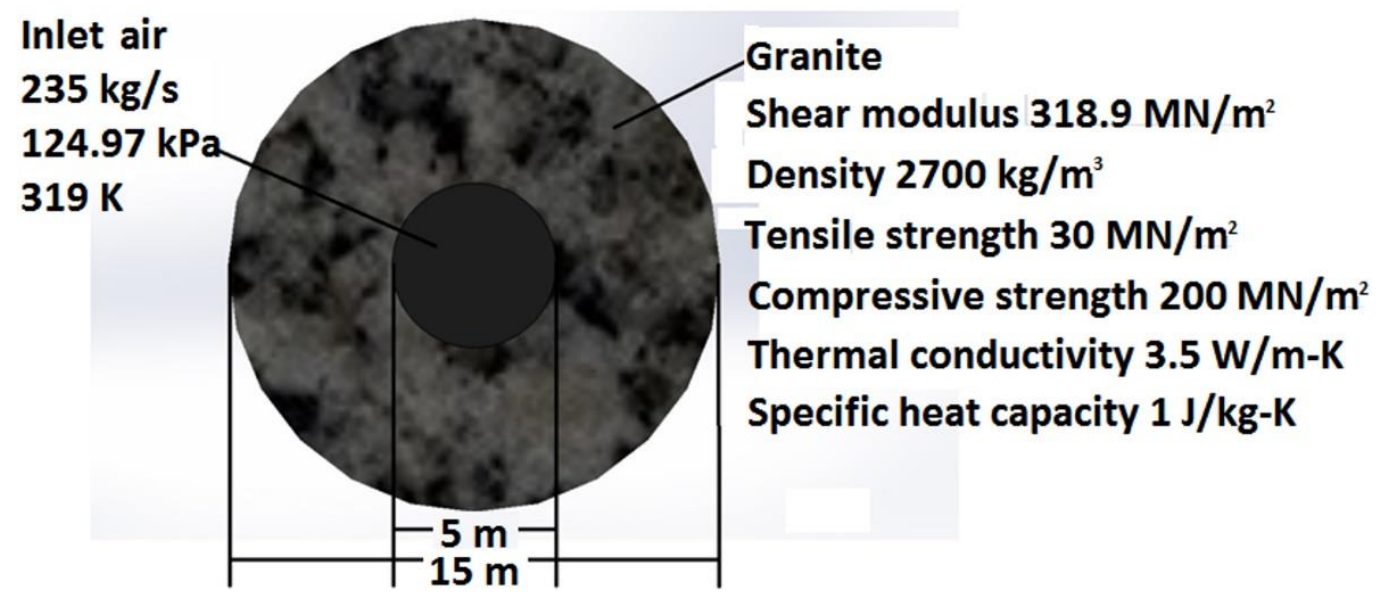

Figure 2 Cross-section of the shaft with the host rock properties and ambient air conditions

In Figure 2, the end view of the $5 \mathrm{~m}$ diameter downcast shaft is shown within the $15 \mathrm{~m}$ diameter granite host rock. The strength properties and density of the host rock are consistent with those of granite in Sudbury, Ontario, and the thermal conductivity was determined experimentally in a separate project. The surface transfer coefficient of the host rock was set to $50 \mathrm{~W} / \mathrm{m}^{2}$, but was maintained at a constant temperature of $325 \mathrm{~K}\left(52^{\circ} \mathrm{C}\right)$, consistent with the local thermal gradient, for this simulation rather than introduce the computational complexity of a temperature gradient when the physical time is only 130 seconds.

The surface conditions of 28 and $19^{\circ} \mathrm{C}$ WB were selected to correspond to those that would be used in the design of a bulk air chiller (BAC), based on the climate history of Sudbury, Ontario, and are used as a baseline for the worst case scenario. The model was calibrated to release the chilling power at the $1,915 \mathrm{~m}$ level for a total flow of $180 \mathrm{~m}^{3} / \mathrm{s}$. In order to advance the modelling of this technology, proprietary software was developed to determine the cryogenic flow and the implications on the ventilation system. Since the cryogenic liquid expands to over 700 litres of gaseous air per one litre of liquid, some of the ventilation air is replaced by the cryogenically sourced air, which decreases the amount of air required to be drawn from the surface by the main fans. A screenshot of the output results is shown in Figure 3. The program was coded to use psychrometric calculations for the determination of the cryogenic liquid requirement needed to provide the necessary chilling, given surface conditions and underground target conditions. The liquid air contains no moisture; thus, will reduce the humidity as per the amount added to the flow. This is reflected in the psychrometric calculations of the software.

The initial condition for inlet air temperature was set to $319 \mathrm{~K}\left(46.5^{\circ} \mathrm{C}\right)$ to agree with the values obtained from the program after the auto-compression has been determined. The required flow rate of $254.9 \mathrm{~kg} / \mathrm{s}$ needed to provide $180 \mathrm{~m}^{3} / \mathrm{s}$ is comprised of the warm inlet airflow entering the shaft, set to $235 \mathrm{~kg} / \mathrm{s}$ and the cold cryogenic sourced outlet air mixing in the shaft, set at 10 to $12 \mathrm{~kg} / \mathrm{s}$ for each outlet. In order to obtain 130 seconds of physical time, the calculations required 700 hours of CPU at this resolution. 


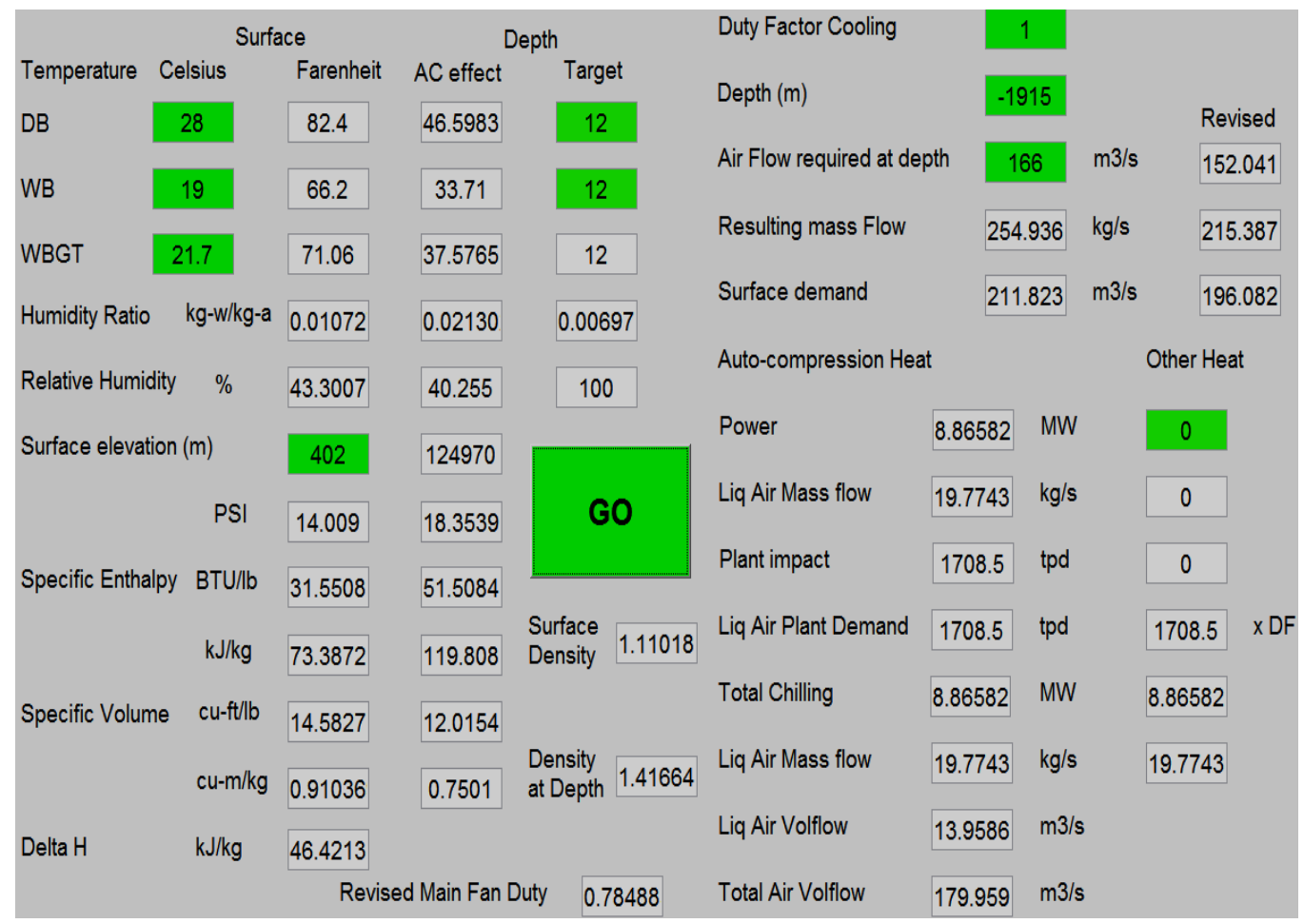

Figure 3 Screenshot of the output, from the proprietary cryogenic software package developed at CanMIND, provides the flow conditions used as the initial conditions for the computational fluid dynamics modelling

The structure of the cryogenic heat exchanger is comprised of a series of 10 concentric cylindrical plates used to transfer the heat from the liquid to the ambient airflow. The tubes for the liquid flow are contained within each concentric cylinder, so the latent heat of vaporisation is absorbed by the ambient airflow along the inner and outer surfaces of the concentric cylinders. The cryogenic liquid absorbs sufficient heat to undergo a phase change from liquid to gas, which provides pressure; thus, a velocity to the cold gas at the outlets. In Figure 4, the heat exchanger and cryogenically sourced air outlets are shown. A central pipe carries the low temperature gas downstream to be released perpendicularly to the ambient airflow as a means of creating mixing turbulence.

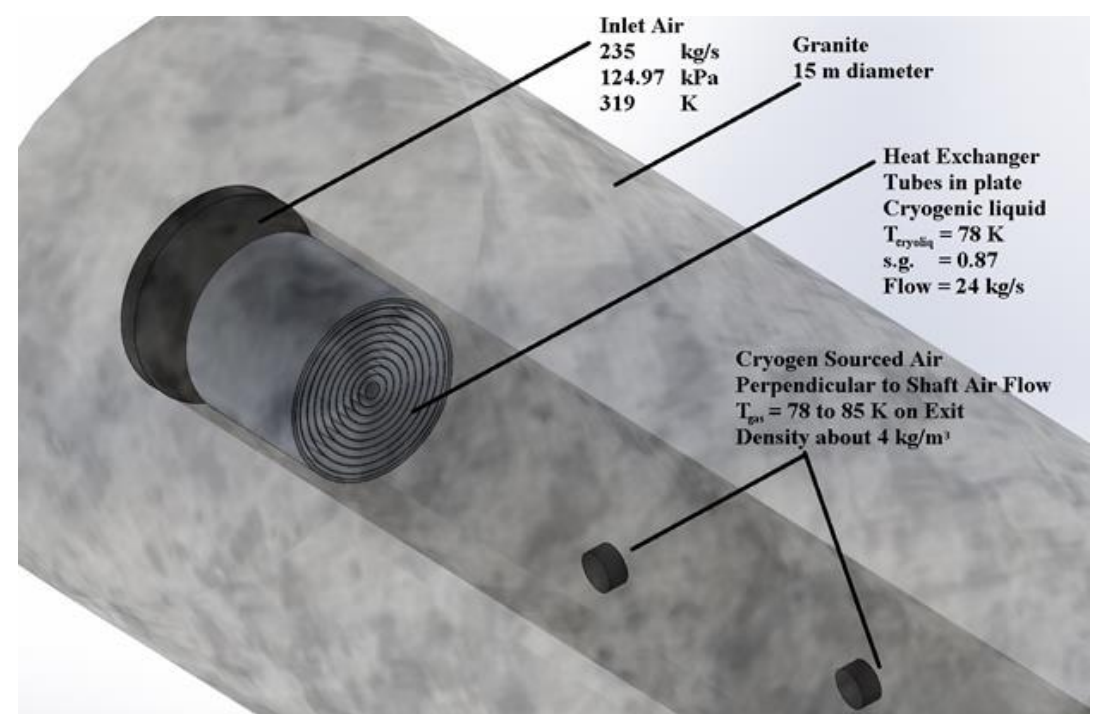

Figure 4 Heat exchanger design and initial conditions used in the computational fluid dynamics model to determine the design effectiveness and chilling power of a cryogenic flow 
In Figure 5, the flow trajectories of the results for Model B are shown with light blue highlights accenting the concentric cylinders of the heat exchanger and the cryogenic air outlets. As the ambient air flows through the gaps between the cylinders, the cryogenic liquid warms and changes state to a gas. The cryogenically sourced gas flow exits the circular outlets seen as light blue discs inside the flow trajectories.

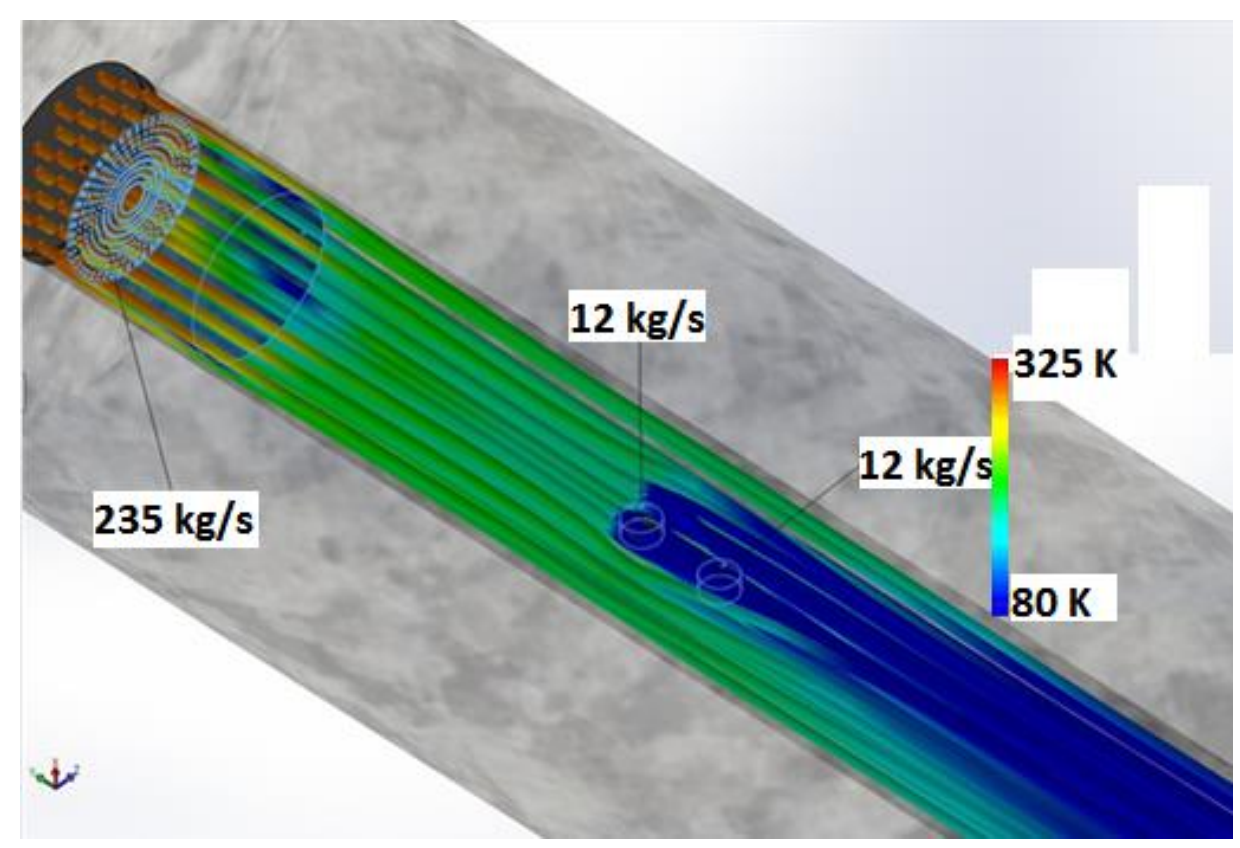

Figure 5 Close-up of the flow trajectories demonstrates the mixing of the two airflows; the warm incoming air at $319 \mathrm{~K}$ cools as it passes the heat exchanger, mixing with the cold air about $80 \mathrm{~K}$

Although several simulations were performed to develop the design, the current design is best described by a simulation with an area of $530.6 \mathrm{~m}^{2}$, a heat transfer coefficient of $39.74 \mathrm{~W} / \mathrm{m}^{2}-\mathrm{K}$, and the average heat flux determined in this simulation was $-9,299.4 \mathrm{~W} / \mathrm{m}^{2}$. From these values, the average steady state heat transfer rate from the cold fluid to the incoming air is determined as $5.16 \mathrm{MW}$, but the response from the start of flow to the steady state is shown in Figure 6. The difference between the exact amount of heat required to cause the change of state is equal to $4.920 \mathrm{MW}$, the calculated difference is only $242 \mathrm{~kW}$; however, the simulation takes into account the turbulence and gradient effects, which supplies a more realistic answer. The value of the heat transfer rate from the simulation upon arriving at stabilisation is $5.162 \mathrm{MW}$, which allows for only a small amount of gas creation, as is desired.

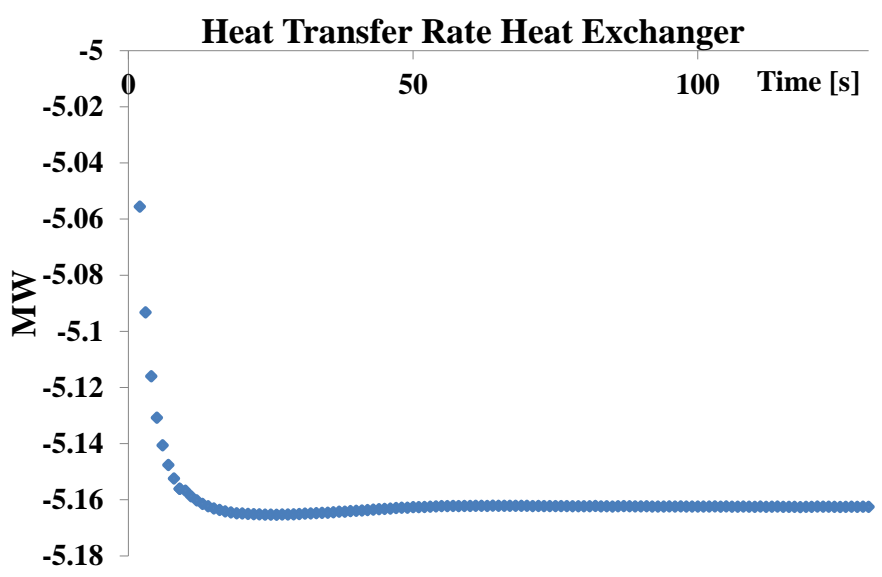

Figure 6 Heat transfer rate simulation for the current design of heat exchanger with an area of $530.6 \mathrm{~m}^{2}$

In Figures 7 and 8, a cross-section at the centre of the shaft illustrates the transition from a transient state as the system flow is initiated to the steady state, which occurs in time frames in the order of about $10 \mathrm{~s}$ or so, rather quickly compared to the response time for currently employed chilling systems. 


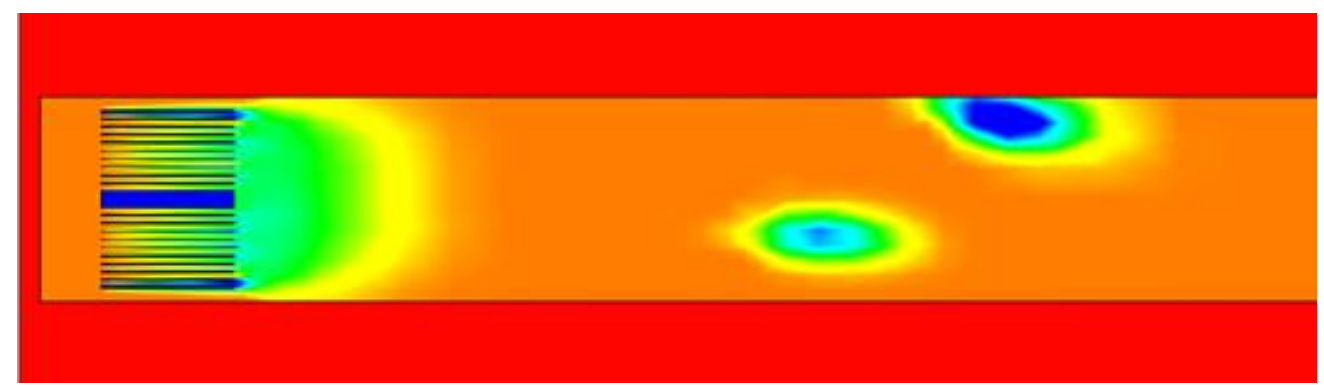

Figure 7 Time from start $=0.56096 \mathrm{~s}$

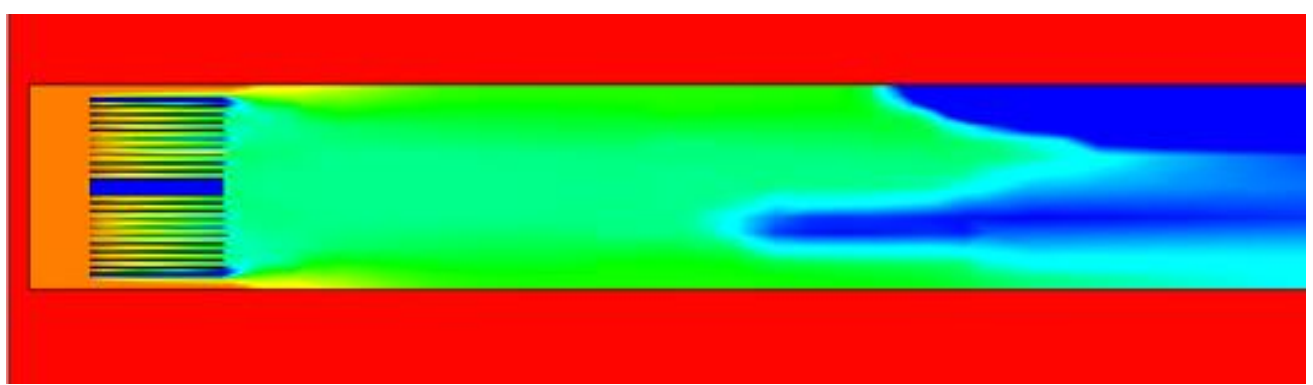

Figure 8 Time from start $=9 \mathrm{~s}$

Cross-sections in Figures 7 and 8 are at the centre of the shaft, the heat exchanger is seen on the left side, and the gaseous flow outlets are at the source of the dark blue flow on the right side. The simulation started at the $1,915 \mathrm{~m}$ level and extended $500 \mathrm{~m}$ to a depth of 2,415 m. Measure of the average temperature of the fluid in the shaft is a means of determining the time taken to reach a steady state. Figure 9 showing the average temperature in the shaft reaching a steady state in about $60 \mathrm{~s}$. The shaft in this simulation is $5 \mathrm{~m}$ in diameter and the density of the air is $1.41 \mathrm{~kg} \cdot \mathrm{m}^{3}$ at the $1,915 \mathrm{~m}$ level, so $235 \mathrm{~kg} / \mathrm{s}$, and corresponds to about $166 \mathrm{~m}^{3} / \mathrm{s}$. Although, in the initial condition of the simulation, the airflow velocity in the simulation is set to $9 \mathrm{~m} / \mathrm{s}$. It quickly settles to about $8.4 \mathrm{~m} / \mathrm{s}$, so for a distance of $500 \mathrm{~m}$, the traversal time is about $59 \mathrm{~s}$. The time taken for the temperature to reach a steady state in the simulation corresponds to the time for the air at the entrance of the shaft to reach the depth, which is a confirmation that there is sufficient mixing over that distance. This is of interest in the design of an installed system, because the distance from the introduction of the cryogen to the ambient airflow, to the point where the temperature is smooth (that is, there are no plumes of ultra cold air), is important from both an operational and a safety perspective.

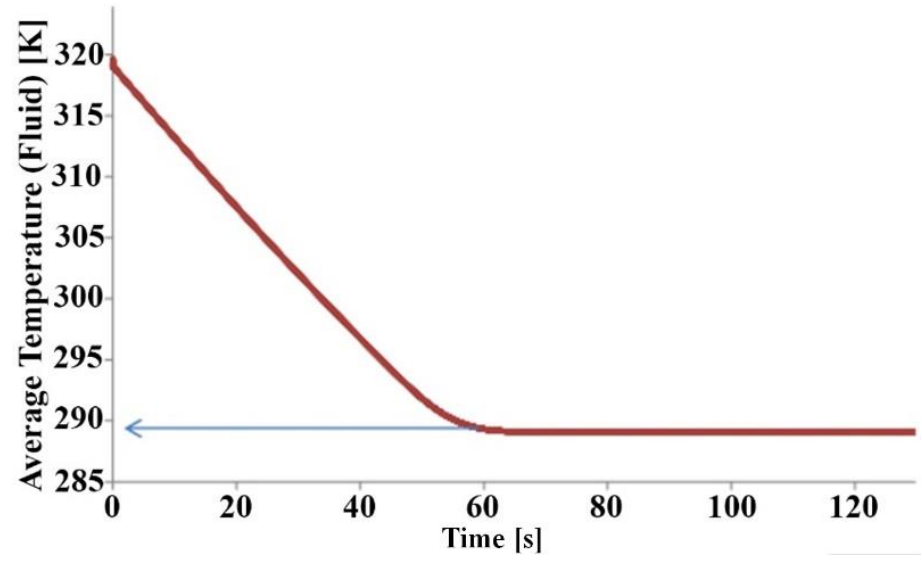

Figure 9 Average air temperature in a $5 \mathrm{~m}$ diameter by $500 \mathrm{~m}$ deep shaft from the time cryogenic flow is initiated at the $1,915 \mathrm{~m}$ depth

The average temperature in the shaft is about $289 \mathrm{~K}\left(17^{\circ} \mathrm{C}\right)$ after about one minute, and remains steady for the remainder of the simulation. 


\section{$3 \quad$ Cryogenic chilling on demand}

The implementation of a cryogenic chilling system in the same manner as a BAC is shown to be feasible, and a preliminary design has been developed and simulated to confirm the interaction of the cryogenically sourced air in terms of the resulting temperatures, temperature profiles, time to steady state, and impact on the ventilation system. One of the significant benefits of using a cryogenic chilling system is that it is a liquid that is being transported to the location where the chilling is required (Cluff et al. 2014). As a result of this fact, the chilling can be easily delivered to specific locations, such as each level, independently, rather than chilling the entire airflow at some higher point. We have developed the concept of Chilling on Demand $^{\mathrm{TM}}$ or $\mathrm{CoD}^{\mathrm{TM}}$ to describe this desirable feature. As a consequence of being able to implement CoD, the mine thermodynamics engineer can determine specific demand and respond to that demand in the order of minutes. We have begun the development of software to control systems based on temperature feedback and have performed simulations to confirm the designs and systems required to deliver CoD.

In the first instance, a smaller system than that required for the downcast shaft, chilling is required for on-the-level chilling, and it is also essential that it be able to produce a higher degree of mixing over a shorter timeframe and distance. A simulation of such a system is shown in Figures 10 and 11 . The mixing is created by using a heat exchanger of the same design as that in the larger shaft chilling system, but with the addition of several outlet vents arranged to push the ultra cold air perpendicularly into the ambient air, which is drawn into the system via a regular mine fan.

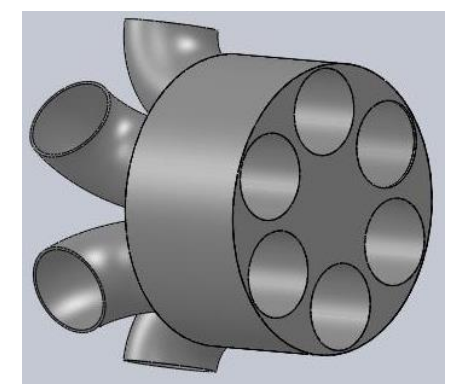

Figure 10 Outlet vent design for a Cryofan used to provide rapid mixing of ultra cold and ambient air

The simulation of the system is shown in Figure 11 by the flow trajectories with the elements removed to allow for a clear view of the turbulent mixing flow trajectories.

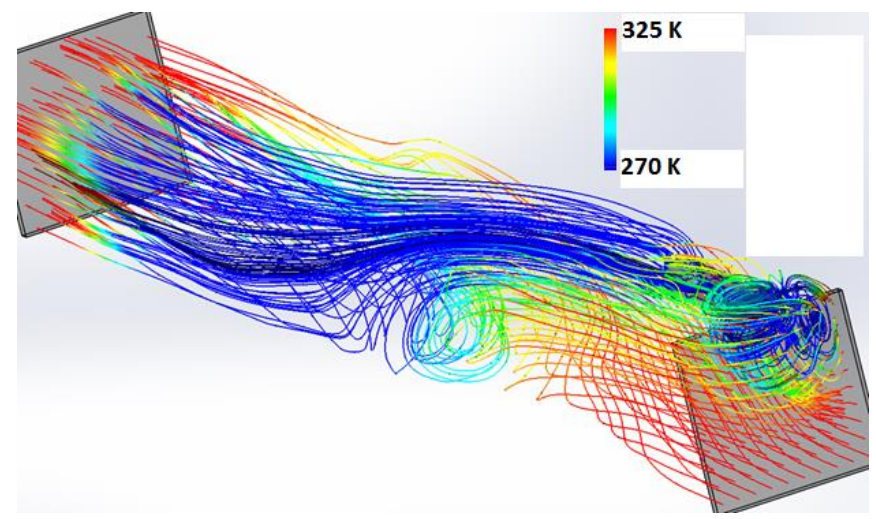

Figure 11 Simulation of outlet vent design for a Cryofan used to provide rapid mixing of ultra cold and ambient air on the level

This simulation was over a distance of $20 \mathrm{~m}$ in the drift and is preliminary, but demonstrates a high degree of turbulent mixing. At the time of writing, further simulations were being developed to increase the length of confinement tubing and to introduce more ambient air; that is, increase the flow drawn by the mine fan.

With the move from diesel and the increased inclusion of electric vehicles in underground operations, there is an expectation that the ventilation requirements may be reduced by 40 to $50 \%$ of that required by the 
current legislation when diesels are used. This also impacts on the return air raise and shaft diameters, the fan power, and chilling requirements (Harris \& Guse 2015). With reduced airflow, the risk of reaching temperatures that exceed acceptable or legislated values is increased due to the inability of the airflow to absorb the energy that is introduced. It is a simple case of the mass flow and the low specific heat capacity of air. The concept of CoD relies on availability of liquid air at or near the entrance to the level. Should the design decision be chilling the bulk flow of air in the down cast shaft, then the result can be achieved but the effectiveness will be diminished due to the distribution of cold air to areas where it is not required; thus, creating cooler areas at a higher cost than would be incurred with a targeted approach.

In order to describe the CoD concept, let us first examine the change in cryogen flow rates for a set of surface conditions as the depth is increased to provide an understanding of the impact on the individual level.

There is an impact on the other variables, such as the reduction in the main fan power and the change in the amount of air required from the surface. The point to be made is that, in the instance of increasing depth, the cost and complexity of either implementation, or expanding other existing technologies, would be compared to simply extending the length of the pipe with installation of the other service elements, such as storage and vaporisers, and be no more complex than a new ventilation fan, at the new depth.

The range of variation under consideration for this example is based on the following surface and underground conditions: the surface elevation is $402 \mathrm{~m}$, the underground target temperature is kept constant at $12 / 12 \mathrm{DB} / \mathrm{WB}^{\circ} \mathrm{C}$ at a volumetric airflow of $180 \mathrm{~m}^{3} / \mathrm{s}$, and the surface conditions vary from $5 / 3$ to $28 / 19 \mathrm{DB} / \mathrm{WB}^{\circ} \mathrm{C}$. These conditions are used to calculate the results shown in Tables 1 to 4 , which correspond to the depths $1,915,2,500,3,000$ and 3,500 $\mathrm{m}$ respectively.

Table 1 Change in liquid air demand for $12 / 12 \mathrm{DB} / \mathrm{WB}{ }^{\circ} \mathrm{C}$ at the 1,915 level with changing surface temperatures

\begin{tabular}{lllllll}
\hline $\begin{array}{l}\text { Surface DB/WB } \\
\text { temperature }\end{array}$ & $\begin{array}{l}\text { Chilling } \\
(\mathbf{M W r})\end{array}$ & $\begin{array}{l}\text { Surface } \\
(\mathrm{kg} / \mathrm{s})\end{array}$ & $\begin{array}{l}\text { Surface } \\
\left(\mathrm{m}^{3} / \mathrm{s}\right)\end{array}$ & $\begin{array}{l}\text { Liquid air } \\
(\mathrm{kg} / \mathrm{s})\end{array}$ & $\begin{array}{l}\text { Liquid air } \\
\left(\mathbf{m}^{3} / \mathrm{s}\right)\end{array}$ & $\begin{array}{l}\text { \% of original } \\
\text { fan power }\end{array}$ \\
\hline $28 / 19$ & 8.86 & 254.94 & 211.82 & 19.77 & 13.95 & 78.48 \\
$25 / 19$ & 8.28 & 255.53 & 211.44 & 18.6 & 13.11 & 79.71 \\
$20 / 16$ & 7.01 & 255.93 & 210.39 & 15.92 & 11.19 & 82.47 \\
$15 / 12$ & 5.69 & 256.91 & 209.81 & 13.07 & 9.16 & 85.49 \\
$10 / 8$ & 4.38 & 257.54 & 208.92 & 10.19 & 7.13 & 88.59 \\
$5 / 3$ & 3.05 & 258.06 & 207.92 & 7.15 & 4.99 & 91.91 \\
\hline
\end{tabular}

Table 2 Change in liquid air demand for $12 / 12 \mathrm{DB} / \mathrm{WB}{ }^{\circ} \mathrm{C}$ at the 2,500 level with changing surface temperatures

\begin{tabular}{lllllll}
\hline $\begin{array}{l}\text { Surface DB/WB } \\
\text { temperature }\end{array}$ & $\begin{array}{l}\text { Chilling } \\
(\mathbf{M W r})\end{array}$ & $\begin{array}{l}\text { Surface } \\
(\mathbf{k g} / \mathbf{s})\end{array}$ & $\begin{array}{l}\text { Surface } \\
\left(\mathbf{m}^{3} / \mathbf{s}\right)\end{array}$ & $\begin{array}{l}\text { Liquid air } \\
(\mathbf{k g} / \mathbf{s})\end{array}$ & $\begin{array}{l}\text { Liquid air } \\
\left(\mathbf{m}^{3} / \mathbf{s}\right)\end{array}$ & $\begin{array}{l}\text { \% of original } \\
\text { fan power }\end{array}$ \\
\hline $28 / 19$ & 10.86 & 266.70 & 218.69 & 23.91 & 16.15 & 75.44 \\
$25 / 19$ & 10.30 & 266.96 & 217.88 & 22.83 & 15.39 & 76.47 \\
$20 / 16$ & 8.97 & 267.86 & 217.12 & 20.12 & 13.52 & 79.12 \\
$15 / 12$ & 7.56 & 268.69 & 216.45 & 17.14 & 11.45 & 82.10 \\
$10 / 8$ & 6.18 & 269.59 & 215.73 & 14.17 & 9.46 & 85.04 \\
$5 / 3$ & 4.7 & 270.61 & 215.15 & 11.04 & 7.34 & 88.26 \\
\hline
\end{tabular}


Table 3 Change in liquid air demand for $12 / 12 \mathrm{DB} / \mathrm{WB}{ }^{\circ} \mathrm{C}$ at the 3,000 level with changing surface temperatures

\begin{tabular}{lllllll|}
\hline $\begin{array}{l}\text { Surface DB/WB } \\
\text { temperature }\end{array}$ & $\begin{array}{l}\text { Chilling } \\
(\mathbf{M W r})\end{array}$ & $\begin{array}{l}\text { Surface } \\
(\mathbf{k g} / \mathbf{s})\end{array}$ & $\begin{array}{l}\text { Surface } \\
\left(\mathbf{m}^{3} / \mathbf{s}\right)\end{array}$ & $\begin{array}{l}\text { Liquid air } \\
(\mathbf{k g} / \mathbf{s})\end{array}$ & $\begin{array}{l}\text { Liquid air } \\
\left(\mathbf{m}^{3} / \mathbf{s}\right)\end{array}$ & $\begin{array}{l}\text { \% of original } \\
\text { fan power }\end{array}$ \\
\hline $28 / 19$ & 12.70 & 276.56 & 224.18 & 27.68 & 18.02 & 72.88 \\
$25 / 19$ & 12.20 & 277.28 & 223.56 & 26.77 & 17.34 & 73.74 \\
$20 / 16$ & 10.82 & 278.23 & 222.86 & 23.99 & 15.52 & 76.30 \\
$15 / 12$ & 9.31 & 279.23 & 222.23 & 20.89 & 13.46 & 79.19 \\
$10 / 8$ & 7.87 & 280.34 & 221.72 & 17.84 & 11.45 & 82.10 \\
$5 / 3$ & 6.35 & 281.62 & 221.30 & 14.57 & 9.32 & 85.26 \\
\hline
\end{tabular}

Table 4 Change in liquid air demand for $12 / 12 \mathrm{DB} / \mathrm{WB}{ }^{\circ} \mathrm{C}$ at the 3,500 level with changing surface temperatures

\begin{tabular}{lllllll}
\hline $\begin{array}{l}\text { Surface DB/WB } \\
\text { temperature }\end{array}$ & $\begin{array}{l}\text { Chilling } \\
(\mathbf{M W r})\end{array}$ & $\begin{array}{l}\text { Surface } \\
(\mathbf{k g} / \mathbf{s})\end{array}$ & $\begin{array}{l}\text { Surface } \\
\left(\mathbf{m}^{3} / \mathbf{s}\right)\end{array}$ & $\begin{array}{l}\text { Liquid air } \\
(\mathbf{k g} / \mathbf{s})\end{array}$ & $\begin{array}{l}\text { Liquid air } \\
\left(\mathbf{m}^{3} / \mathbf{s}\right)\end{array}$ & $\begin{array}{l}\text { \% of original } \\
\text { fan power }\end{array}$ \\
\hline $28 / 19$ & 14.71 & 286.67 & 229.64 & 31.72 & 19.91 & 70.34 \\
$25 / 19$ & 14.29 & 287.57 & 228.96 & 31.02 & 19.42 & 71.00 \\
$20 / 16$ & 12.85 & 288.91 & 228.54 & 28.19 & 17.57 & 73.50 \\
$15 / 12$ & 11.24 & 290.05 & 228.12 & 24.93 & 15.45 & 76.37 \\
$10 / 8$ & 9.70 & 291.36 & 227.71 & 21.77 & 13.44 & 79.22 \\
$5 / 3$ & 8.08 & 292.98 & 227.59 & 18.34 & 11.27 & 82.37 \\
\hline
\end{tabular}

As shown in Tables 1 to 4 , the chilling power required to create the same underground conditions at increasing depths increases. The temperatures used for this example are attainable; however, would not normally be expected to be target temperatures at such depths. These are only used because they are reasonable temperatures for the $1,915 \mathrm{~m}$ level in a situation similar to using a $\mathrm{BAC}$ and allowing the air to flow to a lower level, but in this example the need to maintain a constant underground condition for the ease of comparison is required. Looking at row three, on a typical summer day in Northern Ontario with a temperature of $20 / 16 \mathrm{DB} / \mathrm{WB}^{\circ} \mathrm{C}$, the relative humidity is about $67 \%$. The chilling power increases from $7.01 \mathrm{MW}_{\mathrm{r}}$ at 1,915 to $12.85 \mathrm{MW}_{\mathrm{r}}$ at 3,500, with a corresponding change in cryogenic liquid flow from 15.9 to $28.2 \mathrm{~kg} / \mathrm{s}$ to create the same conditions at each level. Had this temperature been created at the $1,915 \mathrm{~m}$ level using a bulk chilling concept, the temperature would increase as the air proceeded to the $3,500 \mathrm{~m}$ level by about $15^{\circ} \mathrm{C}$, so the air arriving at the $3,500 \mathrm{~m}$ level will be about $27^{\circ} \mathrm{C}$. Alternatively, a trade-off can be created such that the air at the $1,915 \mathrm{~m}$ level is colder to accommodate cooler air reaching the 3,500 $\mathrm{m}$ level. Another aspect discussed earlier is that the liquid air replaces some of the ventilation air. In Tables 1 to 4, the mass flow rate of the cryogenically sourced air is converted to the volumetric flow rate, which takes into account the density on the level where the liquid air is released.

Of note, is that for higher temperature surface conditions, the fan power percentage is reduced more than that for the lower temperature surface conditions. This is due to the need for more chilling, which requires that more cryogenic liquid be released, but a second effect is due to the depth as more chilling is required as the depth increases. The percentage of full fan power required increases in each scenario as the temperature decreases; but also take as an example the $28 / 19 \mathrm{DB} / \mathrm{WB}^{\circ} \mathrm{C}$ in Table 1 compared to the same in Table 4 - the fan power is $74.8 \%$ of full power at the $1,915 \mathrm{~m}$ level and drops to $70.34 \%$ at the $3,500 \mathrm{~m}$ level. Fans are a major power consumer at a mine, so reduction in fan power can lead to 
significant power savings, which is part of the costing concept the authors use to determine the feasibility of cryogenic chilling for a given project.

To further explore the CoD concept, let us consider a case such that the surface conditions are $25 / 19 \mathrm{DB} / \mathrm{WB}^{\circ} \mathrm{C}$ and a requirement that the air delivered to the shaft entrance at 3,000, 3,100, 3,200 and $3,300 \mathrm{~m}$ be a total of $200 \mathrm{~m}^{3} / \mathrm{s}$ at $20 / 18 \mathrm{DB} / \mathrm{WB}^{\circ} \mathrm{C}$ evenly split to $50 \mathrm{~m}^{3} / \mathrm{s}$ per level. For a system similar to a $\mathrm{BAC}$, the target depth for the temperature conditions would be the $3,300 \mathrm{~m}$ level as it is the deepest. This ensures that the target temperature is met at all levels with no increase in temperature due to auto-compression or heat diffusion from the shaft walls. By introducing the chilling at the $3,000 \mathrm{~m}$ level, it is expected that the temperature would increase by $2.94^{\circ} \mathrm{C} \mathrm{DB}$ with the relative humidity remaining fairly constant. This means that at the $3,000 \mathrm{~m}$ level the temperature would have to be adjusted to $17.06 / 15.2 \mathrm{DB} / \mathrm{WB}^{\circ} \mathrm{C}$. The total chilling power required to achieve this is $12.2 \mathrm{MW}_{\mathrm{r}}$ with an associated main fan power reduction to $76 \%$ of that which would be required without the additional gaseous flow due to expansion of the liquid.

Considering the $3,300 \mathrm{~m}$ level flow of $50 \mathrm{~m}^{3} / \mathrm{s}$ at $12 / 12 \mathrm{DB} / \mathrm{WB}{ }^{\circ} \mathrm{C}$, the impact of smaller amounts of heat than usually considered as significant can have substantial effect on the temperature in the locality where the heat is injected. In this scenario, the mass flow of $50 \mathrm{~m}^{3} / \mathrm{s}$ at $1.57 \mathrm{~kg} / \mathrm{m}^{3}$ is $78.7 \mathrm{~kg} / \mathrm{s}$. For simplicity, assume an electric load-haul-dump unit (LHD) that provides $180 \mathrm{~kW}$ of heat on a $100 \%$ duty cycle is the incremental value, and that the strata, fans, broken rock, fixed equipment and electrical stations introduce heat evenly distributed over the level at a rate of $1,100 \mathrm{~kW}$.

Using the same temperatures as before, $12 / 12 \mathrm{DB} / \mathrm{WB}^{\circ} \mathrm{C}$ with the addition of $1,100 \mathrm{~kW}$ to a $100 \mathrm{~m} / \mathrm{s}$ flow on $3,300 \mathrm{~m}$ level raises the temperature to $18.9 / 18.6 \mathrm{DB} / \mathrm{WB}^{\circ} \mathrm{C}$, but if the flow is reduced to $50 \mathrm{~m}^{3} / \mathrm{s}$ on $3,300 \mathrm{~m}$ level, the temperature rise is up to $25.9 / 25.2 \mathrm{DB} / \mathrm{WB}^{\circ} \mathrm{C}$ for the same heat, which is expected to be typically or constantly injected. So using $25 / 19 \mathrm{DB} / \mathrm{WB}^{\circ} \mathrm{C}$ for the surface, and $12 / 12 \mathrm{DB} / \mathrm{WB}{ }^{\circ} \mathrm{C}$ as the underground target temperature, then the chilling power required, just to negate the auto-compression, is $3.73 \mathrm{MW}_{\mathrm{r}}$, which is delivered by $8.1 \mathrm{~kg} / \mathrm{s}$ of cryogenic liquid air. Now consider the incremental injection of $180 \mathrm{~kW}$ as shown in Table 5. The wet bulb globe temperature (WBGT) of $28^{\circ} \mathrm{C}$ is used as a cut-off point or may require the implementation of a work/rest regime.

Table 5 Effect of adding heat to airflow, and the impact of chilling on demand on the 3,300 $\mathrm{m}$ level for a flow of $50 \mathrm{~m}^{3} / \mathrm{s}$ at an initial temperature of $12 / 12 \mathrm{DB} / \mathrm{WB}^{\circ} \mathrm{C}$

\begin{tabular}{|c|c|c|c|}
\hline \multicolumn{2}{|c|}{ Heat added (kW) } & \multirow{2}{*}{$\begin{array}{l}\left.\text { Temperature (DB/WB }{ }^{\circ} \mathrm{C}\right) \\
25.9 / 25.2\end{array}$} & \multirow{2}{*}{$\frac{\text { WBGT }}{25.5}$} \\
\hline Base amount: & 1,100 & & \\
\hline +1 LHD: & 180 & $28.2 / 27.4$ & 27.7 \\
\hline +2 LHD: & 360 & $30.5 / 29.6$ & 29.8 \\
\hline +3 LHD: & 540 & $32.7 / 31.8$ & 32.1 \\
\hline \multicolumn{4}{|c|}{$\begin{array}{l}\text { Increasing the cryogenic liquid airflow from } 8.1 \text { to } 8.7 \mathrm{~kg} / \mathrm{s} \text { raises the } \\
\text { chilling power from } 3.73 \text { to } 4.0 \mathrm{MW}_{\mathrm{r}}\end{array}$} \\
\hline \multicolumn{2}{|c|}{ Total heat added to air $1,640 \mathrm{~kW}$} & $28.7 / 27.7$ & 28 \\
\hline
\end{tabular}

The question becomes: how much heat from each source is injected into the ventilation stream on a given level at a given time? In this scenario, there is a mass flow of $78.7 \mathrm{~kg} / \mathrm{s}$ at a density of $1.574 \mathrm{~kg} / \mathrm{m}^{3}$ on the $3,300 \mathrm{~m}$ level. The variables of density, as they pertain to a given level, airflow velocity and volume, and the static heat injected via strata heating and stationary equipment is taken as a baseline, so the introduction of the variable heat injected due to mobile equipment or operations, such as blasting, becomes the determining factor for the chilling on demand approach.

Considering a second scenario at 2,500 m depth and a density of $1.483 \mathrm{~kg} / \mathrm{m}^{3}$ and a slightly higher flow rate of $60 \mathrm{~m}^{3} / \mathrm{s}$ results in a mass flow of $88.98 \mathrm{~kg} / \mathrm{s}$, which is about $10 \mathrm{~kg} / \mathrm{s}$ more than in the last scenario. For a 
temperature of $12 / 12 \mathrm{DB} / \mathrm{WB}^{\circ} \mathrm{C}$ on the level, obtained from surface conditions of $25 / 19 \mathrm{DB} / \mathrm{WB}{ }^{\circ} \mathrm{C}$, the chilling power required to negate auto-compression is $3.4 \mathrm{MW}_{\mathrm{r}}$.

Table 6 shows the temperature increase as energy is added to the ventilation flow for the initial temperature of $12 / 12 \mathrm{DB} / \mathrm{WB}^{\circ} \mathrm{C}$. Adding the average base amount of $1,100 \mathrm{~kW}$ in one calculation is somewhat misleading, as that heat would be expected to be absorbed by the ventilation stream as the air progresses through the workings, but suitable for the final exit temperature. Additional LHDs are added to the level by adding $180 \mathrm{~kW}$ for each. The limit is reached at two LHDs as the WBGT reaches $27.7^{\circ} \mathrm{C}$, because the addition of the next LHD takes the temperature up to $29.7^{\circ} \mathrm{C}$ WBGT. However, if a temperature sensor feedback system were in place to increase the cryogenic flow, the temperature could be brought back down to $27.7^{\circ} \mathrm{C}$ WBGT by increasing the mass flow from 7.61 to $7.94 \mathrm{~kg} / \mathrm{s}$. For a more comfortable work place, the temperature could be reduced to 25.7 WBGT by increasing the flow from 7.61 to $8.36 \mathrm{~kg} / \mathrm{s}$. These scenarios provide the basics of CoD, and the previously rapid response time available for CoD, as shown in Figure 9, suggests that a reaction to sudden heat introduced on a given level can be dealt with effectively and quickly when the supply of liquid air is available on the level.

Table 6 Effect of adding heat to airflow, and the impact of chilling on demand on the 2,500 $\mathrm{m}$ level for a flow of $60 \mathrm{~m}^{3} / \mathrm{s}$ at an initial temperature of $12 / 12 \mathrm{DB} / \mathrm{WB}^{\circ} \mathrm{C}$

\begin{tabular}{|c|c|c|c|}
\hline \multicolumn{2}{|c|}{ Heat added (kW) } & \multirow{2}{*}{$\begin{array}{l}\left.\text { Temperature (DB/WB }{ }^{\circ} \mathrm{C}\right) \\
24.3 / 23.7\end{array}$} & \multirow{2}{*}{$\frac{\text { WBGT }}{23.8}$} \\
\hline Base amount & 1,100 & & \\
\hline$+1 \mathrm{LHD}$ & 180 & $26.3 / 25.6$ & 25.8 \\
\hline$+2 \mathrm{LHD}$ & 360 & $28.3 / 27.5$ & 27.7 \\
\hline +3 LHD & 540 & $30.4 / 29.4$ & 29.7 \\
\hline \multicolumn{4}{|c|}{$\begin{array}{l}\text { Increase the cryogenic liquid airflow from } 8.1 \text { to } 8.7 \mathrm{~kg} / \mathrm{s} \text { raises the } \\
\text { chilling power from } 3.73 \text { to } 4.0 \mathrm{MW} \text {. }\end{array}$} \\
\hline \multicolumn{2}{|c|}{ Total heat added to air $1,640 \mathrm{~kW}$} & $28.7 / 27.7$ & 28 \\
\hline
\end{tabular}

\subsection{Compressed air supplied by liquid air also chills}

Compressed air is often lost as it is transported through the piping network to the site where it is needed. According to the Ontario Mining Association (da Cunha 2007), compressed air can account for up to $20 \%$ of the costs of underground mining, and from 30 to $70 \%$ of that air is lost through leaks. If the compressed air supply for the mine is based on liquid air, the problem of leaks in compressed air lines becomes nonexistent. Since the liquid air supply is delivered to the level for the purpose of chilling, the compressed air becomes an add-on to the system.

The compressed air system is comprised of standard components, such as the receiver and surge tanks, fittings, and transfer piping that a mine would normally purchase to provide compressed air and would easily be purchased off-the-shelf. The difference is only in the manner in which the compressed air is produced. The volume flow into the receiver tank, based on the required supply as determined by the mine planning and design team, will be supplied by the liquid flow of cryogenic air from the Cryopressure ${ }^{\mathrm{TM}}$ determined on a mass flow basis. This mass flow is calculated from the volume flow demand of the compressed air system by considering the ideal gas law. Since the mass flow is a cryogenic liquid, the pressure is developed by confinement of a gas under an increase in temperature.

In the case of the Cryopressure ${ }^{\mathrm{TM}}$ system, the charging is accomplished by injection of a liquid at an appropriate rate. There are two approaches under consideration at present: (i) the pressure increase due to the increasing temperature of the gas can be exploited in conjunction with an injection valve that can adjust the flow by increasing the frequency of injections to increase the mass flow rate of the cryogen as 
demand requires, and the converse, (ii) a proportional-integral-derivative unit can be adjusted to a single set point that the controls will be continuously striving to achieve.

In Table 7, the chilling power potentially available for a given compressed air requirement is shown. It should be noted that both two basic systems are envisioned. The first being a system comprised of a receiver tank in close proximity to the underground cryogenic storage, which should be close to the entrance of the level, that is connected by standard compressed air piping to serve the level. The second is a mobile system that would be able to supply compressed air and chilling to more remote working zones by taking a liquid air supply and a surge tank system that could be easily transported by a truck. The values in Table 7 are based on $24 \mathrm{hrs} /$ day operation at $830 \mathrm{kPa}$ (120 psi).

Table 7 Chilling provided by Cryopressure for selected compressed air demand

\begin{tabular}{llllllll}
\hline \multicolumn{2}{c}{$\begin{array}{c}\text { Consumption } \\
\left(\mathbf{f t}^{3} / \mathbf{m i n}\right)\end{array}$} & $\begin{array}{l}\text { Receiver } \\
\left(\mathbf{m}^{3} / \mathbf{h r}\right)\end{array}$ & $\begin{array}{l}\text { Chilling } \\
\left(\mathbf{m}^{3}\right)\end{array}$ & $\begin{array}{l}\mathrm{kW} \\
(\mathbf{k W})\end{array}$ & $\begin{array}{l}\text { Mass flow } \\
\left(\mathrm{ft}^{3} / \mathbf{m i n}\right)\end{array}$ & $\begin{array}{l}\text { Liquid flow } \\
(\mathbf{k g} / \mathbf{s})\end{array}$ & $\begin{array}{l}\text { Plant impact } \\
(\mathrm{L} / \mathbf{s})\end{array}$ \\
\hline 500 & 850 & 1.79 & 124 & 0.248 & 0.29 & 0.33 & 25 \\
1,000 & 1,699 & 3.6 & 248 & 0.248 & 0.58 & 0.67 & 50 \\
2,000 & 3,398 & 7.28 & 496 & 0.248 & 1.16 & 1.33 & 100 \\
3,000 & 5,097 & 11.06 & 744 & 0.248 & 1.74 & 2.00 & 150 \\
5,000 & 8,495 & 18.54 & 1,240 & 0.248 & 2.9 & 3.33 & 250 \\
\hline
\end{tabular}

\section{Conclusion}

A concept and preliminary designs for a cryogenic chilling system for both the large-scale for downcast shaft, and for on-the-level chilling, has been presented, and computational fluid dynamics simulations have been undertaken for the verification of the systems' interaction. The issue of the impact of heat on low ventilation flow rates has been addressed by the application of a chilling on demand system. Cryogenics offers the opportunity for simultaneously chilling while providing another service. In this instance, the chilling power for a spectrum of compressed air supply has been shown to be attractive.

\section{Acknowledgement}

Some aspects of this work were financially supported by the Ultra Deep Mining Network and Glencore, which is greatly appreciated. Academic support was provided from the University of Exeter Camborne School of Mines, and business development support from the Centre for Excellence in Mining Innovation.

\section{References}

Brett, G \& Barnett, M 2014, 'The application of liquid air energy storage for large scale long duration solutions to grid balancing', EPJ Web of Conferences, vol. 79, https://doi.org/10.1051/epjconf/20137903002

Cluff, DL, Kennedy, GA \& Foster, PJ 2014, 'Liquid air for energy storage, auto-compression, compressed air and ventilation in deep mining', in M Hudyma \& Y Potvin (eds), Proceedings of the Seventh International Conference on Deep and High Stress Mining, Australian Centre for Geomechanics, Perth, pp. 757-770.

da Cunha, I 2007, Implementing a Sustainable Compressed Air Leak Program, final report of the Ontario Mining Association's compressed air leak management program, Ontario Mining Association, Toronto, viewed 17 July 2017, http://www.oma.on.ca/en/news/index.aspx?keyword=\&date=07/01/2007\&newsld=0184a317-4fa8-45c9-b60eb9d8da4211a5

Harris, C \& Guse, T 2016, Opportunity for battery powered fleet within the Onaping Depth Project, presentation at MeMo 2016: The Maintenance, Engineering and Reliability/Mine Operators Conference, The Canadian Institute of Mining, Metallurgy and Petroleum, Westmount, presentation 1424. 